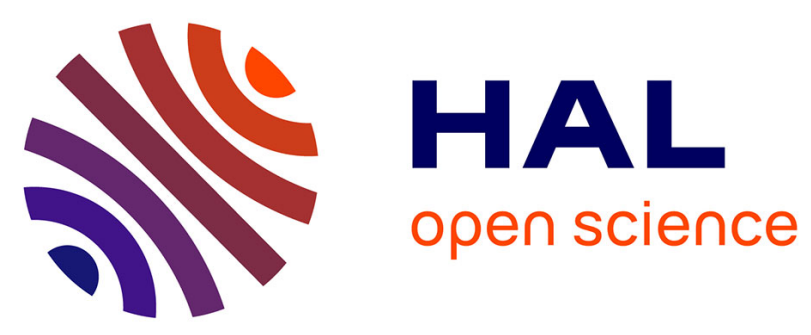

\title{
Reduced survival in patients with ALS with upper airway obstructive events on non-invasive ventilation
}

Marjolaine Georges, Valérie Attali, Jean Louis Golmard, Capucine

Morélot-Panzini, Lise Crevier-Buchman, Jean-Marc Collet, Anne Tintignac, Elise Morawiec, Valery Trosini-Desert, François Salachas, et al.

\section{To cite this version:}

Marjolaine Georges, Valérie Attali, Jean Louis Golmard, Capucine Morélot-Panzini, Lise CrevierBuchman, et al.. Reduced survival in patients with ALS with upper airway obstructive events on non-invasive ventilation. Journal of Neurology, Neurosurgery and Psychiatry, 2016, 10.1136/jnnp2015-312606 . hal-01325417

\section{HAL Id: hal-01325417 https: / hal.sorbonne-universite.fr/hal-01325417}

Submitted on 2 Jun 2016

HAL is a multi-disciplinary open access archive for the deposit and dissemination of scientific research documents, whether they are published or not. The documents may come from teaching and research institutions in France or abroad, or from public or private research centers.
L'archive ouverte pluridisciplinaire HAL, est destinée au dépôt et à la diffusion de documents scientifiques de niveau recherche, publiés ou non, émanant des établissements d'enseignement et de recherche français ou étrangers, des laboratoires publics ou privés. 


\section{Reduced survival in ALS patients}

\section{with upper airway obstructive events on noninvasive ventilation}

Marjolaine Georges (1,2); Valérie Attali (2,3); Jean Louis Golmard (4); Capucine MorélotPanzini (1,2); Lise Crevier-Buchman (5); Jean-Marc Collet (3); Anne Tintignac (1); Elise Morawiec (1); Valery Trosini-Desert (1); François Salachas (6); Thomas Similowski $(1,2)$; Jesus Gonzalez-Bermejo $(1,2)$.

1. AP-HP, Groupe Hospitalier Pitié-Salpêtrière Charles Foix, Département "R3S", Service de Pneumologie et Réanimation Médicale, F-75013, Paris, France

2. Sorbonne Universités, UPMC Univ Paris 06, INSERM, UMRS1158 Neurophysiologie respiratoire expérimentale et clinique, Paris, France

3. AP-HP, Groupe Hospitalier Pitié-Salpêtrière Charles Foix, Département "R3S", Service des Pathologies du Sommeil, F-75013, Paris, France

4. AP-HP, Groupe Hospitalier Pitié-Salpêtrière Charles Foix, Département de biostatistiques, F-75013, Paris, France

5. AP-HP, Hôpital Européen Georges Pompidou, Unité de la Voix, Service ORL et Chirurgie Cervico-Faciale, Paris, France

5. Université Paris Descartes, CNRS UMR 7018, Paris

6. AP-HP, Groupe Hospitalier Pitié-Salpêtrière Charles Foix, Département de Neurologie et Centre de Référence pour la SLA, F-75013, Paris, France

Running head: Upper airway obstruction on NIV in ALS

Correspondence: jesus.gonzalez@aphp.fr 


\section{Abstract: 247 words}

Noninvasive ventilation (NIV) is part of standard care in amyotrophic lateral sclerosis (ALS). Intolerance or unavailability of NIV, as well as the quality of correction of nocturnal hypoventilation have a direct impact on prognosis.

Objectives : We describe the importance of NIV failure due to upper airway obstructive events, the clinical characteristics, as well as their impact on the prognosis of ALS.

Methods : Restrospective analysis of the data of 190 patients with ALS and NIV in a singlecenter for the period 2011 to 2014. 179 patients tolerating NIV for more than 4 hours per night without leaks were analysed.

Results : Among the 179 patients, after correction of leaks, 73 remained inadequately ventilated at night (defined as more of $5 \%$ of the night spent at $<90 \%$ of $\mathrm{SpO} 2$ ), as a result of obstructive events in $67 \%$ of cases $(n=48)$. Patients who remained inadequately ventilated after optimal adjustment of ventilator settings presented shorter survival than adequately ventilated patients. Unexpectedly, patients with upper airway obstructive events without nocturnal desaturation and in whom no adjustment of treatment was therefore performed also presented shorter survival. On initiation of NIV, no difference was demonstrated between patients with and without upper airway obstructive events. In all patients, upper airway obstruction was concomitant with reduction of ventilatory drive.

Conclusions : This study shows that upper airway obstruction during NIV occurs in ALS patients and is associated with poorer prognosis. Such events should be indentified as they can be corrected by adjusting ventilator settings. 


\section{Introduction}

Amyotrophic lateral sclerosis (ALS) is a neurodegenerative disease of unknown origin. After onset of the first symptoms, the median survival without respiratory assistance is 19 months ${ }^{1}$ and about 7 months in patients with documented diaphragmatic involvement ${ }^{2}$. Most deaths are due to respiratory causes ${ }^{3}$. For these reasons, noninvasive ventilation (NIV) is now part of standard care of $\mathrm{ALS}^{4,5}$. By delivering positive pressure ventilatory assistance via a nasal or face mask, NIV relieves dyspnea and improves quality of life ${ }^{6}$. The survival benefit of NIV has been reported to range from 7 months $^{7}$ to 12 months or more ${ }^{8,9}$. Intolerance of NIV or lack of availability of $\mathrm{NIV}^{8,9}$ is a missed opportunity to improve quality of life and prognosis ${ }^{4}$. However, initiation of NIV is more difficult in ALS patients than in patients with other neuromuscular diseases ${ }^{10}$, while the quality of correction of nocturnal hypoventilation has a direct impact on prognosis ${ }^{11}$. The failure of NIV to maintain satisfactory ventilation at night is related to the presence of leaks in more than one half of cases ${ }^{11}$, but other mechanisms, sometimes associated, are also involved, including upper airway obstructive events, central events comprising reduction of the ventilatory drive, and patient-ventilator asynchrony ${ }^{11,12}$. When nocturnal hypoventilation persists after correction of leaks, it is recommended to perform respiratory polygraphy during NIV to identify the mechanisms responsible ${ }^{13}$. We describe the role of upper airway obstructive events in failure of NIV in patients with ALS, their clinical characteristics, and their intrinsic prognostic impact. 


\section{Material and Methods}

\section{Background}

This single-center observational study was conducted in the Department of Respiratory Medicine and Medical Intensive Care of a 1600-bed university hospital. This department is associated with the rare diseases reference center for ALS in the same hospital. Initiation and surveillance of NIV in ALS patients is performed in an 8-bed day-care unit, according to a recently validated model $^{14}$, which devotes $80 \%$ of its activity to the management of respiratory failure in $\mathrm{ALS}^{11}$.

\section{Patients}

Between 2011 and 2012, NIV was initiated in our center in 190 patients with definite or probable ALS according to El Escorial criteria ${ }^{15}$, and the patients' outcome was followed until 2014. NIV was well tolerated (NIV $>4 \mathrm{~h} / 24 \mathrm{~h}$ ) by 179 of these patients ${ }^{8}$ (Figure 1 ). All these 179 patients were included in the analysis. Analysis of these data was approved by the Institutional Review Board of the Société de Pneumologie de Langue Française (French learned society for respiratory medicine), and all patients provided their written informed consent to the anonymous use of their personal data. All the patients received riluzole, and, as appropriate, secretions management with In/Exsuffflator and gastrostomy. The patients and their caregivers all received logistical and psychological support by the Paris ALS Network care $^{16}$

\section{Respiratory management and evaluation}

The indication for NIV was based on the current consensual criteria ${ }^{5}$. NIV was initiated according to the current standardized procedure in the department, over a period of 3 to 5 days $^{17}$ (Table 1). During the follow up, the effectiveness of NIV was assessed in terms of symptoms (including NIV-related discomfort), blood gases, the analysis of ventilator- 
recorded tracings and nocturnal oximetry. This was performed in all patients in a systematic manner after one month of NIV (M1) and then every three months, as previously described in in detail ${ }^{11}$. Patients were considered to be inadequately ventilated (16) at night when they presented nocturnal $\mathrm{SpO}_{2}<90 \%$ for more than $5 \%$ of the nocturnal recording time ${ }^{11}$. Built-in monitoring software was used to detect air leaks, which were then corrected. In the absence of leaks ${ }^{18}$, ventilator software were able to detect with good accuracy possible obstructive events (see previously report for details ${ }^{11}$ ) (Figure 2) and nap polygraphy (or polysomnography for 5 patients) was then performed in all the patients inadequately ventilated and who were suspected to have upper airway obstructive events (Figure 2$)^{13}$. An obstructive event on NIV was defined by $a \geq 50 \%$ drop in airflow for 10 seconds or longer ${ }^{19}$ with no concomitant changes in the amplitude of the pressure signal ${ }^{13}$ and was considered to be associated with reduction in ventilatory drive ${ }^{13}$ when it occurred in the absence of associated thoracoabdominal paradox ${ }^{19}$. The absence of obstructive events was defined by an obstruction index $<5 / \mathrm{h}$ on the ventilator software ${ }^{20}$. All the patients were ventilated with a respiratory backup rate, to provide for central apneas ${ }^{13}$. Pharyngolaryngeal assessment was also performed by nasal endoscopy (Pentax, VNL-1190STK), during spontaneous breathing in 11 patients and noninvasive ventilation in 1 patient (Figure 3 and supplementary video on line).

\section{Interventions in case of inadequate ventilation due to obstructive events}

After correction of the leaks, the corrective interventions in patients were, in this order : 1/ step by step increase in expiratory positive airway pressure (EPAP) to a maximum of 10 $\mathrm{cmH} 20$ if tolerated; 2/ trial use of self-adapting inspiratory pressure devices (IVAPS mode, Resmed, Sydney, Australia; AutoAdvanced, Philips Respironics, Pensylvania, USA); 3/ switch to volume-controlled mode; 4/ trial of other mechanical treatments (mandibular advancement device, cervical collar). 


\section{Statistical analysis}

Descriptive statistics used numbers and percentages for qualitative variables and Quantitative variables were described in terms of their median and interquartile range because of strong skewness in some distributions. Comparisons between groups of patients used $\mathrm{Chi}^{2}$ tests for qualitative variables and Wilcoxon-Mann-Whitney tests for quantitative variables. Prognostic factors were analyzed in the framework of survival analysis. Survival time was defined as the time between first signs of the disease and date of death. Patients alive at the date of analysis were considered to be censored at this date. Survival functions were estimated by the KaplanMeier method and between-group comparisons were tested by log-rank tests. All computations were performed by SAS V9.3 (SAS Institute Inc, Cary, NC, USA).

\section{Results}

After correction of leaks, 106 of the 179 patients evaluated were considered to be adequately ventilated at night (group 1) and 73 remained inadequately ventilated (group 2) (supplementary Table 2 on line and Figure 1).

In group 2, for 49 patients (67\% of inadequately ventilated patients), poor ventilation was due to obstructive events (group $2 \mathrm{O}+$ ). Correction was obtained in 21 of these 49 patients after adjustment of ventilator settings (Group $2 \mathrm{O}+/$-) (titration of EPAP up to $10 \mathrm{~cm} \mathrm{H}_{2} \mathrm{O}$ guided by polygraphy and tolerance, followed, in the case of failure, by a trial of automatic modes (Figure 2) and finally a trial of volume-controlled mode). Obstructive events could not be eliminated in 28 patients despite adjustment of ventilator settings (group $2 \mathrm{O}+/+$ ). In this case, ventilator settings were adjusted to ensure the least residual apneas and the best subjective tolerance.

In group 1, 38 patients presented upper airway obstructive events (Group $1 \mathrm{O}+$ ). However, in the absence of nocturnal desaturation and symptoms, no change of treatment was proposed in 
this group.

Results of pharyngolaryngeal endoscopic assessment in 11 patients are listed in the online supplement (Figure 3 and supplementary video on line).

Patients who remained inadequately ventilated after optimization of NIV settings (to uncorrected obstructions (group $2 \mathrm{O}+/+$ ) or other causes (group $2 \mathrm{O}-$ )) presented shorter survival (respectively 14[7-27] months and 12[6-23]months) than ventilated patients without or corrected upper airway obstructive events (group $1 \mathrm{O}$ - and group $2 \mathrm{O}+/$-) (respectively 26[13-45]months ( $\mathrm{p}=0.04$ and 0.03) and 29[20-53]months, $(\mathrm{p}=0.01$ and 0.01))(Figure 4). Unexpectedly, patients with upper airway obstructive events without nocturnal desaturation, in whom no adjustment of treatment was therefore proposed (Group $1 \mathrm{O}+$ ), had a shorter survival (13[7-40]months) than that of adequately ventilated patients without upper airway obstructive events after adjustments group $2 \mathrm{O}+/-(\mathrm{p}=0.026)$; and a survival that was not significantly different from that of patients considered to be inadequately ventilated.

In the light of these results, we compared patients without and with upper airway obstructive events on the first recording $(\mathrm{O}-, \mathrm{n}=92$, i.e. $51 \%$ and $\mathrm{O}+, \mathrm{n}=87$, i.e. $49 \%$, respectively). No significant difference was demonstrated between $\mathrm{O}+$ and $\mathrm{O}-$ patients at the time of initiation of NIV (Table 1), except that Group O- comprised more patients with bulbar onset ALS (24 patients versus $12, \mathrm{p}=0.034)$, but with no significant difference of the bulbar score at the time of initiation of NIV and that GroupO- comprised more patients with gastrostomy ( $\mathrm{n}=21$, $23 \%$, vs. $\mathrm{n}=9,10 \%$, in group $\mathrm{O}+, \mathrm{p}=0.02$ ), without difference in survival in patients with or without gastrostomy in the whole group. In the adequately ventilated patients, the patients with upper airway obstructive events had more desaturations but all less than $5 \%$ of the night, and a shorter use of NIV (supplementary Table 3 on line).

In all $\mathrm{O}+$ patients, obstructive events were consistently associated with a reduction of ventilatory drive (Figure 2). In the 20 patients in whom complete PSG was performed, 
obstructive events predominantly occurred during REM sleep, but were always associated with loss of accessory respiratory muscle activity.

None of the patients presented hyperventilation on NIV (Table 1), and no significant difference in variations of $\mathrm{PaCO}_{2}$ without and with NIV were observed between $\mathrm{O}+$ patients and O- patients.

The majority of patients were ventilated with a face mask, with no significant difference between the 2 groups.

$\mathrm{O}+$ patients presented more criteria of NIV failure: diurnal alveolar hypoventilation was less well controlled by NIV $\left(\mathrm{PaCO}_{2}\right.$ : 50 [44-55] mmHg versus 43 [41-48] mmHg in O- patients, $\mathrm{p}<0.001$ and $67 \%$ of $\mathrm{O}+$ patients $(\mathrm{n}=57)$ were hypercapnic $\left(\mathrm{PaCO}_{2}>45 \mathrm{mmHg}\right)$ on NIV versus $34 \%$ of $O-$ patients $(n=37), p<0.001$.

Effective interventions in patients of group $2 \mathrm{O}+(\mathrm{n}=49)$ were: $1 /$ increased expiratory positive airway pressure (EPAP) to the maximum of our protocol $(10 \mathrm{~cm} \mathrm{H} 20)$ for 18 patients (Figure 2) 2/ use of self-adapting inspiratory pressure devices in 8 patients (IVAPS mode, Resmed, Sydney, Australia or AutoAdvanced mode, Philips Respironics, Pensylvania,USA) for 3 patients, 3/ switch to volume-controlled mode in 1 patient (VT 500ml, Ti1,3 EPAP 4). Other treatments were tried without success: custom-made mandibular advancement device, as also recently described by Veldhuis et al. ${ }^{21}$, was tried in addition to NIV in 4 patients, but was discontinued after 3 to 6 months due to poor tolerance. Due to the possible role of the oronasal mask, the oronasal mask was replaced by a nasal mask, which was not supported by the patients concerned due to air leaks. Anterior dislocation of the jaw using a cervical collar was tried, but without success, in 3 patients.

\section{Discussion}

This study confirms that upper airway obstruction is one of the mechanisms of NIV failure in 
ALS $^{10,11,21,22}$. The prevalence of upper airway obstruction, which has not been previously systematically evaluated, is high ( $45 \%$ of our patients after correction of leaks). It is noteworthy that NIV-related upper airway obstructive events in ALS patients appear to be mediated by central mechanisms, as obstructive events (defined as cessation or marked decrease of flow with maintained airway pressure) are associated with decreased or abolished thoracoabdominal movements (Figure 2). Finally, obstructive events in this setting are associated with poorer prognosis, even when they do not reduce the efficacy of NIV to correct desaturations (group $1 \mathrm{O}$ - patients) (Figure 4). Correction of obstructive events improves survival (Figure 4).

\section{Putative mechanisms}

\section{Abnormal upper airway collapsibility in ALS}

A number of ALS-related factors can theoretically increase upper airway collapsibility. Upper airway involvement has been extensively described in this disease, particularly in the pharynx and laryn $x^{23,24}$, due to degeneration of corticobulbar fibers, with bilateral glossopharyngeal and hypoglossal nerve lesions, responsible for so-called "bulbar" symptoms with impairment of voice and swallowing, atrophy of the tongue with fasciculations and abnormal corticobulbar reflexes ${ }^{23,25}$. very heterogeneous appearances in endoscopy were observed, ranging from a completely normal airway to complete collapse of the entire airway (Figure 3 and supplementary video online). However, recent studies in ALS have confirmed that the endoscopic appearance of the pharynx and larynx may be normal despite spontaneous and permanent electromyographic activity of the tongue in a great majority of patients ${ }^{26}$, although demonstration of fasciculations is limited by the marked difficulty of obtaining complete relaxation of the tongue (only $6 \%$ of patients ${ }^{25}$ ). More simply, DePaul et al. demonstrated decreased strength of the tongue in almost all patients, even in patients with no dysarthria or swallowing disorders ${ }^{24}$. Decreased strength of the tongue would constitute a predisposing 
factor to increased upper airway collapsibility and we believe that the prevalence of this abnormality in ALS (with or without an obvious bulbar lesion) is probably severely underestimated. Clinical evaluation (bulbar score) and nasal endoscopy are clearly unable to identify patients at high-risk of upper airway collapse when treated by NIV, indicating the need for a specific diagnostic approach. We did not have enough data to differenciate bulbar and pseudobulbar patients, a differenciation that should be explored in future studies. Finally, other mechanisms, described in different diseases, may also be responsible of upper airway obstruction; these include chronic irritation of the surface of the pharynx ${ }^{27} 28$, a higher propensity of the airways to collapse at low lung volume ${ }^{29,30}$ or upper airway nocturnal redistribution of interstitial fluid ${ }^{31}$ for example.

\section{NIV-related inhibition of compensatory mechanisms}

ALS-related obstructive events are observed only during sleep and/or NIV, suggesting the existence of wakefulness-related compensatory mechanisms that have been shown to involve cortical processes. A similar finding has been observed in obstructive sleep apnea syndrome (OSAS), in which snoring and obstructive events are not observed during wakefulness despite the fact that the upper airways of OSAS patients present anatomical and functional abnormalities predisposing to airway collapse. These abnormalities are compensated by increased ventilatory drive to upper airway dilator muscles ${ }^{32,33}$, in which a specific cortical drive participates ${ }^{34}$. NIV could affect this compensation via several mechanisms. Firstly, NIV may reduce $\mathrm{PaCO}_{2}$, which would decrease global ventilatory drive and which could promote glottal closure phenomena in the same way as induction of hypocapnia in healthy subjects ${ }^{35}$. Secondly NIV could induce mechanical inhibition of ventilatory drive, independent of any variations in $\mathrm{CO}_{2}$, and related to changes in thoracic afferents ${ }^{36}$ and their cortical processing ${ }^{37}$, as NIV abolishes the cortical activity related to breathing that characterizes some ALS patients, which has been interpreted to be a compensatory mechanism ${ }^{38}$. Finally, a third 
mechanism could be related to sleep induction, as described in OSAS ${ }^{39}$.

\section{Prognostic impact}

In the patients of this series, obstructive events were associated with poorer prognosis, without any obvious confounder for low survival (smoking habits, riluzole use, respiratory secretions management and nutritionnal support). Of note, the presence of a gastrostomy was less often noted in the patients with obstuctive events, probably because of the lower number of bulbar patients in this group (Table 1). We did not find any difference in survival between patients with or without gastrostomy, as all the patients received nutritional support. We were surprised to find that a poorer survival was observed not only in patients considered to be inadequately ventilated but also in patients considered to be adequately ventilated, i.e. with no nocturnal desaturations (group $1 \mathrm{O}+$ patients). Nocturnal $\mathrm{SpO}_{2}$ monitoring is therefore probably not sufficiently precise to detect poor quality sleep in patients with obstructive events or the criteria of nocturnal $\mathrm{SpO}_{2}<90 \%$ for more than $5 \%$ of the nocturnal recording time $^{11}$ could be to high as suggested in Table 3 . However, this is an important point, as correction of obstructive events is associated with improved survival. The present study shows that adjustments of ventilator settings can control obstructive events in $58 \%$ of cases, with no survival difference between patients corrected during treatment and those who were immediately adequately ventilated. The most frequently effective treatment was to try to reduce upper airway collapsibility by increasing EPAP to high levels. Unfortunately, this was not always effective and no therapeutic intervention effective in all patients has yet been identified. Nethertheless, these difference in survival must be analysd with caution in this not controlled, retrospective study and should be confirmed in futur controlled studies.

In conclusion, upper airway obstructive events associated with decreased ventilatory drive and promoted by NIV are observed in more than half of ventilated ALS patients. The presence of this phenomenon must be systematically investigated, as it can be corrected by adjusting ventilator settings in the majority of cases. Although the retrospective and single- 
center design of this study limits its impact, obstructive events nevertheless appear to be an important phenomenon with an impact on survival. 
Table 1: Patient characteristics

\begin{tabular}{|c|c|c|c|c|c|}
\hline & $\mathrm{n}$ & $\begin{array}{c}\text { Group O- } \\
(\mathrm{n}=92)\end{array}$ & $\mathrm{n}$ & $\begin{array}{c}\text { Group } \mathrm{O}+ \\
(\mathrm{n}=87)\end{array}$ & $\mathrm{p}$ \\
\hline \multicolumn{6}{|l|}{ Anthropometric data } \\
\hline $\begin{array}{l}\text { Age } \\
\text { (years) }\end{array}$ & 92 & $64.6[57.3-71.9]$ & 87 & $63.6[57.1-72.1]$ & NS \\
\hline $\begin{array}{l}\text { Gender } \\
\text { (number of men - \%) }\end{array}$ & 40 & $55[60 \%]$ & 41 & 58 [67\%] & NS \\
\hline $\begin{array}{l}\text { Body Mass Index } \\
\left(\mathrm{kg} \cdot \mathrm{m}^{-2}\right)\end{array}$ & 90 & $23.1[19.6-25.9]$ & 87 & 21.8 [19.1-25.0] & NS \\
\hline $\begin{array}{l}\text { Smoking greater than } 20 \text { pack- } \\
\text { years (number of patients - \%) }\end{array}$ & 38 & $0[0-10]$ & 40 & $0[0-10]$ & NS \\
\hline \multicolumn{6}{|l|}{ Neurological assessment } \\
\hline $\begin{array}{l}\text { Time from onset to diagnostic } \\
\text { (months) }\end{array}$ & 92 & $9[5-17]$ & 86 & $12[6-16]$ & NS \\
\hline $\begin{array}{l}\text { Time from onset to NIV } \\
\text { (months) }\end{array}$ & 68 & $24[11-39]$ & 64 & $22[13-35]$ & NS \\
\hline ALSFRS-R score (/48) & 85 & 40 [35-43] & 85 & $40[36-43]$ & $\mathrm{NS}$ \\
\hline Bulbar onset $(\mathrm{n}-\%)$ & 89 & $24(27)$ & 86 & $12(14)$ & 0.03 \\
\hline Norris bulbar score (/39) & 72 & 36 [31-39] & 84 & 38 [32-39] & NS \\
\hline $\begin{array}{l}\text { Gastrostomy in the follow up } \\
\text { (number of patients-\%) }\end{array}$ & 92 & $21(23 \%)$ & 87 & $9(10 \%)$ & 0.02 \\
\hline \multicolumn{6}{|l|}{ Respiratory assessment } \\
\hline VC sitting/supine (L) & $58 / 63$ & $\begin{array}{l}1.46[0.92-2.05] \\
1.02[0.54-1.65]\end{array}$ & $65 / 62$ & $\begin{array}{l}1.44[1.12-2.05] \\
1.01[0.77-1.53]\end{array}$ & NS \\
\hline $\begin{array}{l}\text { VC sitting/supine } \\
\text { (\% predicted) }\end{array}$ & $58 / 63$ & $\begin{array}{l}40.5[31-54] \\
39.5[28-52] \\
\end{array}$ & $65 / 62$ & $\begin{array}{l}39[32-53] \\
33[27-46] \\
\end{array}$ & NS \\
\hline $\begin{array}{l}\mathrm{Pi}_{\mathrm{MAX}} \\
(\mathrm{cmH} 20 \text { and } \% \text { predicted })\end{array}$ & 66 & $\begin{array}{l}21[12-31] \text { and } \\
21[12-34]\end{array}$ & 60 & $\begin{array}{c}24[13-55] \text { and } \\
25[14-55]\end{array}$ & NS \\
\hline $\begin{array}{l}\text { SNIP } \\
(\mathrm{cm} \mathrm{H} 20 \text { and } \% \text { predicted })\end{array}$ & 68 & $\begin{array}{c}19[12-26] \text { and } \\
19[13-28]\end{array}$ & 59 & $\begin{array}{c}20[14-36] \text { and } \\
24[16-36]\end{array}$ & 0.04 \\
\hline Cough peak flow $(\mathrm{L} / \mathrm{mn})$ & 81 & $160[110-250]$ & 66 & $120[70-200]$ & NS \\
\hline pH before NIV/on NIV & 61 & $\begin{array}{l}7.41[7.39-7.43] \\
7.42[7.41-7.43] \\
\end{array}$ & 73 & $\begin{array}{l}7.41[7.40-7.43] \\
7.41[7.40-7.43] \\
\end{array}$ & NS \\
\hline $\begin{array}{l}\mathrm{PaCO}_{2} \text { before NIV/on NIV } \\
(\mathrm{mmHg})\end{array}$ & $91 / 87$ & $\begin{array}{l}48[43-52] \\
43[41-48]\end{array}$ & $85 / 87$ & $\begin{array}{l}49[46-55] \\
50[44-55]\end{array}$ & $\begin{array}{c}\mathrm{NS} \\
<0.001\end{array}$ \\
\hline deltaPaCO $(\mathrm{mm} \mathrm{Hg})$ & 86 & $4[11-10]$ & 85 & $1[11-10]$ & NS \\
\hline $\begin{array}{l}\mathrm{PaO} 2 \text { before NIV/on NIV } \\
(\mathrm{mmHg})\end{array}$ & $60 / 87$ & $\begin{array}{l}73[67-82] \\
78[70-85]\end{array}$ & $72 / 87$ & $\begin{array}{l}75[68-82] \\
78[72-86]\end{array}$ & $\begin{array}{l}\text { NS } \\
\text { NS }\end{array}$ \\
\hline $\begin{array}{l}\text { TS90 before NIV/on NIV } \\
\text { (\% of recording) }\end{array}$ & $77 / 84$ & $\begin{array}{c}30[11-75] \\
0[0-5]\end{array}$ & $64 / 79$ & $\begin{array}{c}24[7-66] \\
7[1-17]\end{array}$ & $\begin{array}{c}\mathrm{NS} \\
<0.001\end{array}$ \\
\hline \multicolumn{6}{|c|}{ Noninvasive ventilation parameters } \\
\hline IPAP $\left(\mathrm{cm} \mathrm{H}_{2} \mathrm{O}\right)$ & 92 & $13[12-14]$ & 87 & $13[12-15]$ & NS \\
\hline EPAP $\left(\mathrm{cm} \mathrm{H}_{2} \mathrm{O}\right)$ & 92 & $4[4-4]$ & 87 & $4[4-6]$ & 0.01 \\
\hline $\mathrm{RR}\left(. \mathrm{min}^{-1}\right)$ & 91 & $16[14-16]$ & 86 & $16[14-16]$ & $\mathrm{NS}$ \\
\hline NIV use (hours per day) & 87 & $10[8-14]$ & 84 & $8[6-10]$ & $<0.001$ \\
\hline Estimated $\mathrm{Vt}^{7}$ & 86 & $440[390-510]$ & 84 & $417[355-472]$ & 0.04 \\
\hline Leaks $\left(1 \cdot \mathrm{min}^{-1}\right)$ & 86 & $1[0-16]$ & 84 & $1[0-6]$ & NS \\
\hline Face mask $(\mathrm{n}-\%)$ & 91 & $75[69-82]$ & 87 & $75[68-80]$ & NS \\
\hline
\end{tabular}

Results are expressed as median [IQR]

Abbreviations: ALSFRS-R revised Amyotrophic Lateral Sclerosis - Functional Rating Scale, RR back-up respiratory rate, EPAP: expiratory positive airway pressure, IPAP: inspiratory positive airway pressure, NIV: noninvasive ventilation, $\mathrm{PaO}_{2}$ : arterial oxygen tension, $\mathrm{PaCO}_{2}$ : arterial carbon dioxide tension, PiMax: maximal inspiratory mouth pressure (measured from functional residual capacity), SNIP: Sniff Nasal Inspiratory Pressure (measured from functional residual capacity), TS90: time spent with transcutaneous pulsed oxygen saturation less than $90 \%$, VC: vital capacity, Vt: tidal volume. NS : not significant 
Figure legends

Figure 1: Flowchart of the patients included

Figure 2: Upper part : Example of decreased nocturnal $\mathrm{SpO}_{2}$ recorded on polysomnography with reduction of flow (arrows) despite effective ventilator pressure, indicating obstruction associated with reduction or even absence of thoracoabdominal muscle movements. This obstructive event was corrected by increasing EPAP (circle).

Lower part : same event recorded by the ventilator built-in monitoring software showing decreased flow rate (arrows) despite effective ventilator pressure (Rescan ${ }^{\mathrm{TM}}$, Resmed, Sydney, Australia).

Figure 3: Awake nasopharyngeal fiberoptic endoscopy on spontaneous breathing (upper part) and on NIV (lower part) : Immediate obstruction of the upper airway at all the levels, from the tongue to the glottis

Figure 4: Patient survival, from onset of disease, according to the presence of obstructive events, whether or not they were corrected.

Group 1 O-: Group of patients without obstructive events and immediately adequately ventilated.

Group $1 \mathrm{O}+$ : Group of patients with obstructive events considered to be adequately ventilated.

Group 2 O-: Group of inadequately ventilated patients without leaks or obstructive events.

Group $2 \mathrm{O}+/-$ : Group of patients with obstructive events, inadequately ventilated then adequately ventilated after treatment.

Group $2 \mathrm{O}+/+$ : Group of patients with obstructive events, inadequately ventilated and remaining inadequately ventilated after treatment. 
1. Morgan RK, McNally S, Alexander M, Conroy R, Hardiman O, Costello RW. Use of Sniff nasal-inspiratory force to predict survival in amyotrophic lateral sclerosis. Am J Respir Crit Care Med 2005;171:269-74.

2. Arnulf I, Similowski T, Salachas F, et al. Sleep disorders and diaphragmatic function in patients with amyotrophic lateral sclerosis. Am J Respir Crit Care Med 2000;161:849-56.

3. Gil J, Funalot B, Verschueren A, et al. Causes of death amongst French patients with amyotrophic lateral sclerosis: a prospective study. Eur J Neurol 2008;15:1245-51.

4. Heiman-Patterson TD, Miller RG. NIPPV: a treatment for ALS whose time has come. Neurology 2006;67:736-7.

5. Andersen PM, Abrahams S, Borasio GD, et al. EFNS guidelines on the clinical management of amyotrophic lateral sclerosis (MALS)--revised report of an EFNS task force. Eur J Neurol 2012;19:360-75.

6. Bourke SC, Bullock RE, Williams TL, Shaw PJ, Gibson GJ. Noninvasive ventilation in ALS: indications and effect on quality of life. Neurology 2003;61:171-7.

7. Bourke SC, Tomlinson M, Williams TL, Bullock RE, Shaw PJ, Gibson GJ. Effects of non-invasive ventilation on survival and quality of life in patients with amyotrophic lateral sclerosis: a randomised controlled trial. Lancet Neurol 2006;5:140-7.

8. Aboussouan LS, Khan SU, Meeker DP, Stelmach K, Mitsumoto H. Effect of noninvasive positive-pressure ventilation on survival in amyotrophic lateral sclerosis. Ann Intern Med 1997;127:450-3.

9. Lo Coco D, Marchese S, Pesco MC, La Bella V, Piccoli F, Lo Coco A. Noninvasive positive-pressure ventilation in ALS: predictors of tolerance and survival. Neurology 2006;67:761-5.

10. Laub M, Midgren B. Survival of patients on home mechanical ventilation: a nationwide prospective study. Respir Med 2007;101:1074-8.

11. Gonzalez-Bermejo J, Morelot-Panzini C, Arnol N, et al. Prognostic value of efficiently correcting nocturnal desaturations after one month of non-invasive ventilation in amyotrophic lateral sclerosis: a retrospective monocentre observational cohort study. Amyotroph Lateral Scler Frontotemporal Degener 2013;14:373-9.

12. Atkeson AD, RoyChoudhury A, Harrington-Moroney G, Shah B, Mitsumoto H, Basner RC. Patient-ventilator asynchrony with nocturnal noninvasive ventilation in ALS. Neurology 2011;77:549-55.

13. Gonzalez-Bermejo J, Perrin C, Janssens JP, et al. Proposal for a systematic analysis of polygraphy or polysomnography for identifying and scoring abnormal events occurring during non-invasive ventilation. Thorax 2012;67:546-52.

14. Berlowitz DJ, Howard ME, Fiore JF, Jr., et al. Identifying who will benefit from non-invasive ventilation in amyotrophic lateral sclerosis/motor neurone disease in a clinical cohort. J Neurol Neurosurg Psychiatry 2015.

15. Brooks BR, Miller RG, Swash M, Munsat TL. El Escorial revisited: revised criteria for the diagnosis of amyotrophic lateral sclerosis. Amyotroph Lateral Scler Other Motor Neuron Disord 2000;1:293-9.

16. Cordesse V, Sidorok F, Schimmel P, Holstein J, Meininger V. Coordinated care affects hospitalization and prognosis in amyotrophic lateral sclerosis: a cohort study. BMC Health Serv Res 2015;15:134. 
17. Sheers N, Howard ME, Berlowitz DJ. Ambulatory adaptation of non-invasive ventilation in motor neuron disease: where limits of effectiveness end--reply. Amyotroph Lateral Scler Frontotemporal Degener 2015;16:139-40.

18. Janssens JP, Borel JC, Pepin JL. Nocturnal monitoring of home non-invasive ventilation: the contribution of simple tools such as pulse oximetry, capnography, builtin ventilator software and autonomic markers of sleep fragmentation. Thorax 2011;66:438-45.

19. Berry RB, Budhiraja R, Gottlieb DJ, et al. Rules for scoring respiratory events in sleep: update of the 2007 AASM Manual for the Scoring of Sleep and Associated Events. Deliberations of the Sleep Apnea Definitions Task Force of the American Academy of Sleep Medicine. J Clin Sleep Med 2012;8:597-619.

20. Georges M, Adler D, Contal O, et al. Reliability of Apnea-Hypopnea Index Measured by a Home Bi-Level Pressure Support Ventilator Versus a Polysomnographic Assessment. Respir Care 2015;60:1051-6.

21. Veldhuis SK, Doff MH, Stegenga B, Nieuwenhuis JA, Wijkstra PJ. Oral appliance to assist non-invasive ventilation in a patient with amyotrophic lateral sclerosis. Sleep Breath 2014.

22. Boentert M, Brenscheidt I, Glatz C, Young P. Effects of non-invasive ventilation on objective sleep and nocturnal respiration in patients with amyotrophic lateral sclerosis. J Neurol 2015;262:2073-82.

23. Chen A, Garrett CG. Otolaryngologic presentations of amyotrophic lateralsclerosis. Otolaryngol Head Neck Surg 2005;132:500-4.

24. DePaul R, Abbs JH, Caligiuri M, Gracco VL, Brooks BR. Hypoglossal, trigeminal, and facial motoneuron involvement in amyotrophic lateral sclerosis. Neurology 1988;38:281-3.

25. Kent RD, Sufit RL, Rosenbek JC, et al. Speech deterioration in amyotrophic lateral sclerosis: a case study. J Speech Hear Res 1991;34:1269-75.

26. Tankisi H, Otto $M$, Pugdahl K, Fuglsang-Frederiksen A. Spontaneous electromyographic activity of the tongue in amyotrophic lateral sclerosis. Muscle Nerve 2013;48:296-8.

27. Kimoff RJ, Sforza E, Champagne V, Ofiara L, Gendron D. Upper airway sensation in snoring and obstructive sleep apnea. Am J Respir Crit Care Med 2001;164:250-5.

28. van der Graaff MM, Grolman W, Westermann EJ, et al. Vocal cord dysfunction in amyotrophic lateral sclerosis: four cases and a review of the literature. Arch Neurol 2009;66:1329-33.

29. Series F, Cormier Y, Lampron N, La Forge J. Influence of lung volume in sleep apnoea. Thorax 1989;44:52-7.

30. Heinzer RC, Stanchina ML, Malhotra A, et al. Lung volume and continuous positive airway pressure requirements in obstructive sleep apnea. Am J Respir Crit Care Med 2005;172:114-7.

31. Redolfi S, Yumino D, Ruttanaumpawan P, et al. Relationship between overnight rostral fluid shift and Obstructive Sleep Apnea in nonobese men. Am J Respir Crit Care Med 2009;179:241-6.

32. Mezzanotte WS, Tangel DJ, White DP. Waking genioglossal electromyogram in sleep apnea patients versus normal controls (a neuromuscular compensatory mechanism). J Clin Invest 1992;89:1571-9.

33. Lo YL, Jordan AS, Malhotra A, et al. Influence of wakefulness on pharyngeal airway muscle activity. Thorax 2007;62:799-805. 
34. Launois C, Attali V, Georges M, et al. Cortical Drive to Breathe during Wakefulness in Patients with Obstructive Sleep Apnea Syndrome. Sleep 2015.

35. Jounieaux V, Aubert G, Dury M, Delguste P, Rodenstein DO. Effects of nasal positive-pressure hyperventilation on the glottis in normal sleeping subjects. J Appl Physiol (1985) 1995;79:186-93.

36. Fauroux B, Isabey D, Desmarais G, Brochard L, Harf A, Lofaso F. Nonchemical influence of inspiratory pressure support on inspiratory activity in humans. J Appl Physiol (1985) 1998;85:2169-75.

37. Hopkinson NS, Sharshar T, Dayer MJ, Lofaso F, Moxham J, Polkey MI. The effect of acute non-invasive ventilation on corticospinal pathways to the respiratory muscles in chronic obstructive pulmonary disease. Respir Physiol Neurobiol 2012;183:41-7.

38. Georges M, Moraviec E, Raux M, Gonzalez-Bermejo J, Pradat P-F, Similowski T, Morélot-Panzini C. Cortical drive to breathe in amyotrophic lateral sclerosis: a dyspnoea-worsening defense. Eur Respir J 2016.

39. Fogel RB, Trinder J, White DP, et al. The effect of sleep onset on upper airway muscle activity in patients with sleep apnoea versus controls. J Physiol 2005;564:54962. 
Funding statement:

"This work was supported by the program "Investissement d'Avenir ANR-10-AIHU 06 of the French Government »

Competing Interests statement:

The authors have no conflict of interest to declare

Contributorship Statement

1.Conception and design,

2. Acquisition of data

3. Analysis

4. Interpretation of data

5. Drafting the work or revising

Marjolaine Georges (1, 2, 3, 4, 5); Valérie Attali (1, 2, 3, 4, 5); Jean Louis Golmard (1,3,4,5); Capucine Morélot-Panzini (1, 2, 3, 4, 5); Lise Crevier-Buchman (1,2,4,5); Jean-Marc Collet $(2,4)$; Anne Tintignac (1,2,5); Elise Morawiec $(1,2,5)$; Valery Trosini-Desert $(1,2,5)$; François Salachas (1,3,4,5); Thomas Similowski $(1,3,4,5)$; Jesus Gonzalez-Bermejo $(1,2,3,4,5)$. 


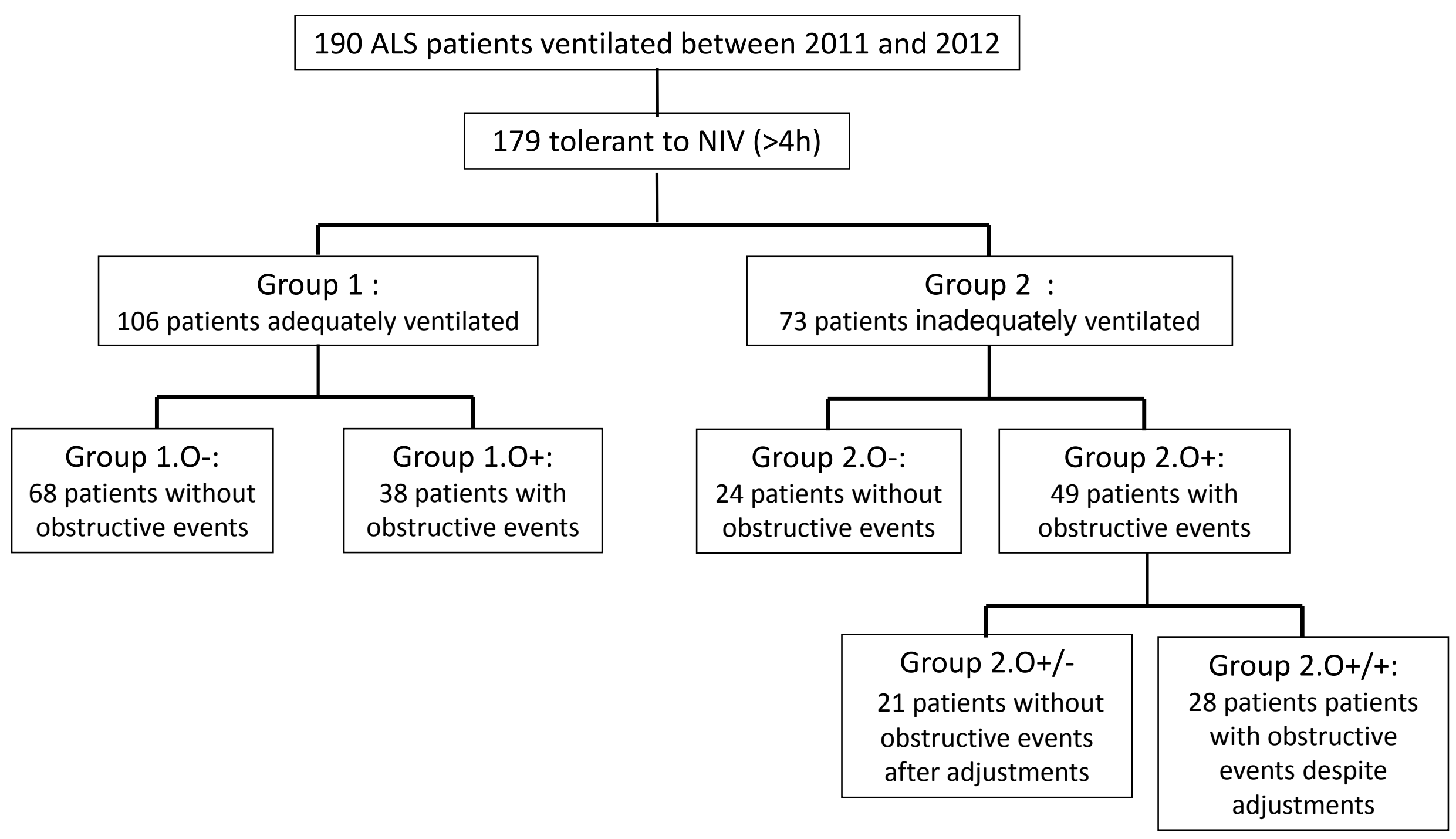





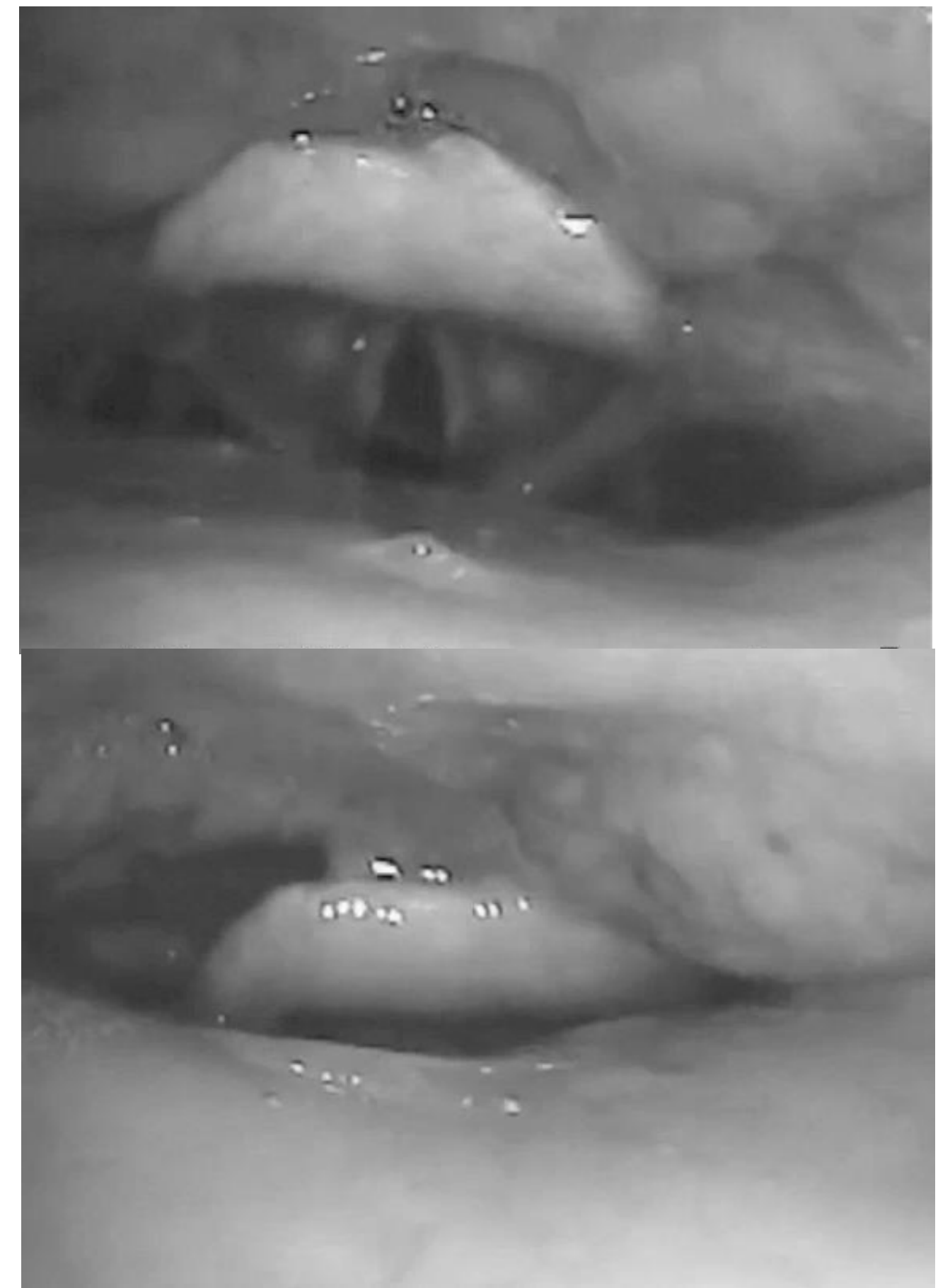

Figure 3 


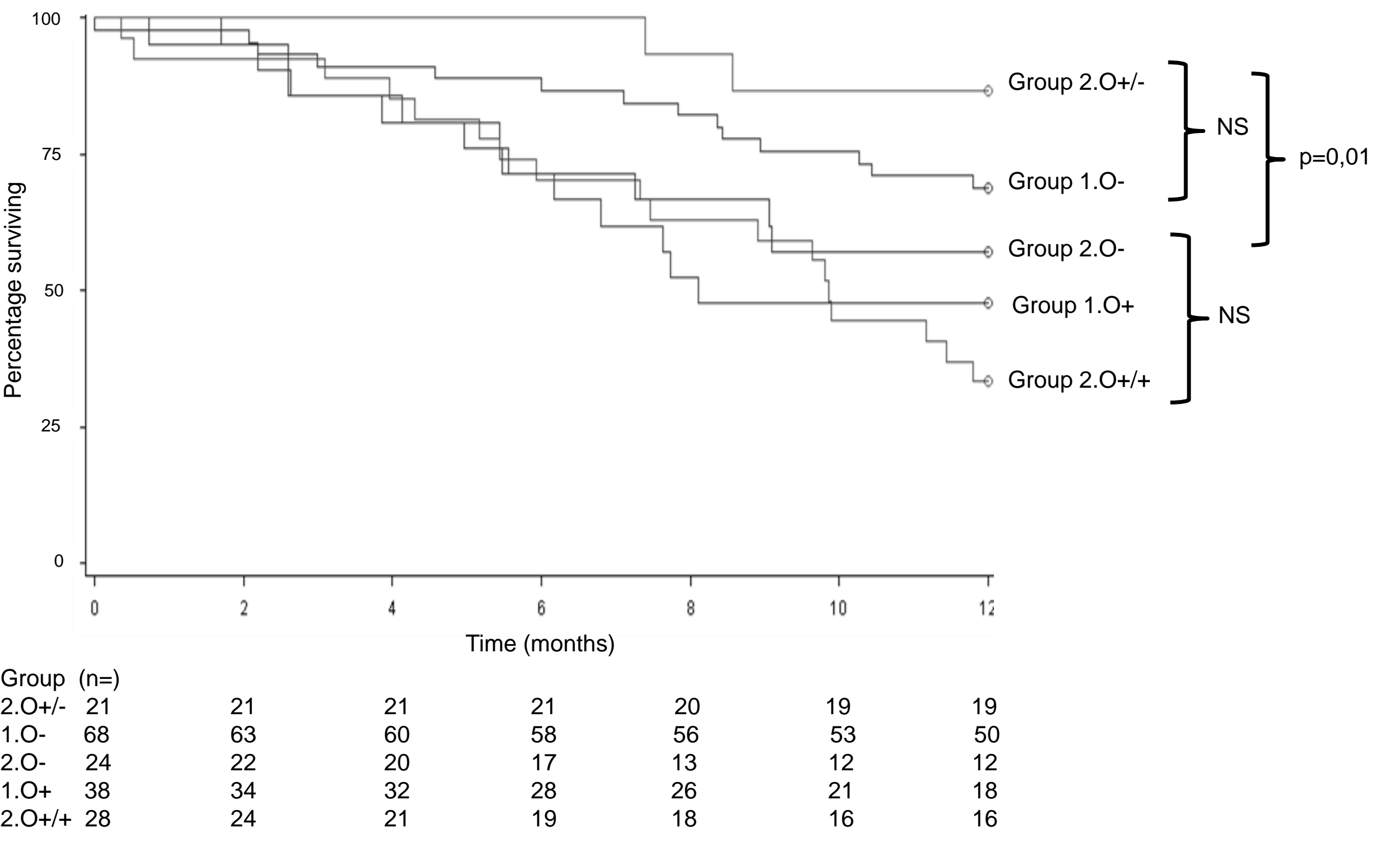

Figure 4 